This item was submitted to Loughborough's Research Repository by the author.

Items in Figshare are protected by copyright, with all rights reserved, unless otherwise indicated.

\title{
Formation of Ag3Sn plates in SnAgCu solder bumps
}

PLEASE CITE THE PUBLISHED VERSION

http://dx.doi.org/10.1016/j.msea.2009.12.020

PUBLISHER

(c) Elsevier

VERSION

AM (Accepted Manuscript)

LICENCE

CC BY-NC-ND 4.0

REPOSITORY RECORD

Gong, Jicheng, Changqing Liu, Paul P. Conway, and Vadim V. Silberschmidt. 2019. "Formation of Ag3sn Plates in Snagcu Solder Bumps". figshare. https://hdl.handle.net/2134/13466. 
This item was submitted to Loughborough's Institutional Repository (https://dspace.lboro.ac.uk/) by the author and is made available under the following Creative Commons Licence conditions.

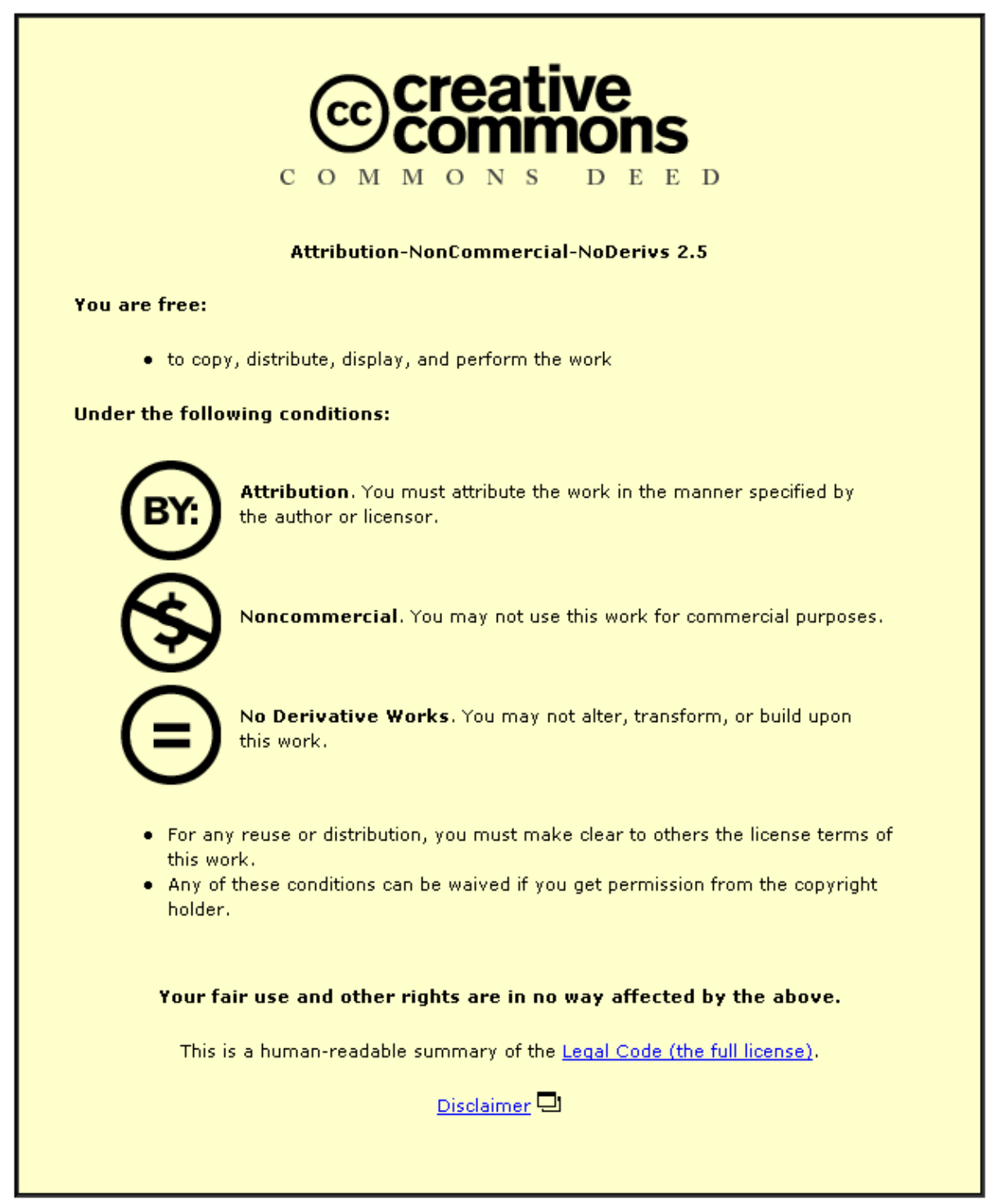

For the full text of this licence, please go to: http://creativecommons.org/licenses/by-nc-nd/2.5/ 


\title{
Formation of $\mathrm{Ag}_{3} \mathrm{Sn}$ Plates in $\mathrm{SnAgCu}$ Solder Bumps
}

\author{
Jicheng Gong ${ }^{\mathrm{a}}$, Changqing Liu ${ }^{\mathrm{b}}$, Paul P. Conway ${ }^{\mathrm{b}}$, Vadim V. Silberschmidt ${ }^{\mathrm{b}}$ \\ ${ }^{a}$ Department of Materials, University of Oxford, Parks Road, Oxford, OX1 3PH, UK \\ ${ }^{\mathrm{b}}$ Wolfson School of Mechanical and Manufacturing Engineering \\ Loughborough University, Loughborough, LE11 3TU, UK
}

\begin{abstract}
Special experiments are designed to obtain the solid reactants directly from a liquid solder during phase transformation. Series of such tests performed throughout reflow, which enables to investigate the entire formation process of intermetallic $\mathrm{Ag}_{3} \mathrm{Sn}$ plates out of liquid $\mathrm{SnAgCu}$ solder bumps. The results show that $\mathrm{Ag}_{3} \mathrm{Sn}$ plates are formed first in the middle of the cooling stage. In the plane, they have two preferable growth directions. By varying thermal conditions during reflow, the formation mechanism of these plates is discussed.
\end{abstract}

Key words: solder; solidification; crystal growth; intermetallics

\section{Introduction}

In the eutectic $\mathrm{SnAgCu}$ solder, one of the most promising $\mathrm{Pb}$-free materials for interconnections in electronic packages, $\mathrm{Ag}$ is basically introduced to reduce the melting point as well as modify metallurgical and mechanical characteristics of this alloy. During soldering, $\mathrm{Ag}$ combines with $\mathrm{Sn}$, forming $\mathrm{Ag}_{3} \mathrm{Sn}$ intermetallic compounds (IMCs). In 
normal cases, $\mathrm{Ag}_{3} \mathrm{Sn}$ IMCs are present in $\beta$-Sn matrix in the form of small particles (or fibres), composing eutectics in a $\mathrm{SnAgCu}$ grain [1-3]. However, such particles are not the only morphology of $\mathrm{Ag}_{3} \mathrm{Sn}$ IMCs. Sometimes, large $\mathrm{Ag}_{3} \mathrm{Sn}$ plates, which can stretch across the entire joint, are found [3-5]. Since $\mathrm{Ag}_{3} \mathrm{Sn}$ plates are brittle and their size in some cases is comparable with that of the joint, their morphology and distribution can play an important role in mechanical properties, and, consequently, influence the reliability of the joint. It has been reported that cracks can initiate and propagate along the interface between $\mathrm{Ag}_{3} \mathrm{Sn}$ plates and the solder [6, 7], and that the existence of $\mathrm{Ag}_{3} \mathrm{Sn}$ plates can reduce joint's

ductility $[8,9]$. Therefore, the formation of these unusual plates has attracted considerable attention [10-12]. Thorough investigations are required. In this paper, an experiment, which is able to capture $\mathrm{Ag}_{3} \mathrm{Sn}$ IMC plates in a molten $\mathrm{SnAgCu}$ solder at an arbitrary moment of reflow, is implemented. By a series of these tests through reflow, the nucleation and growth behaviour of $\mathrm{Ag}_{3} \mathrm{Sn}$ in a $\mathrm{SnAgCu}$ solder material is present. Based on the results from reflow with varying thermal conditions, their formation mechanism is discussed.

\section{Experiments}

In order to obtain the solid reactants out of the liquid solder, one possible solution is to terminate the liquid-to-solid phase transformation by removing the molten solder in the middle of reflow. The experiments are specially designed with this aim. Sketch of the setup is present in Fig. 1a. A circle printed circuit board (PCB) specimen is prepared with $\mathrm{Cu}$ pads on the edge. The solder materials are placed on $\mathrm{Cu}$ pads. The PCB specimen is fixed to spindle, and inserted into an oven. The temperature of solder bumps is measured via a 
thermal couple. When the solder bump reaches a specific temperature during reflow, spinning of the spindle is triggered. The remaining liquid solder is removed from the $\mathrm{Cu}$ pads due to the centrifugal force, leaving there only solid reactants. By a series of these spinning tests at different moments of reflow, the whole process of formation of solid reactants out of the liquid phase can be present. The solder material applied in this study is a commercial $\mathrm{Sn} 3.8 \mathrm{Ag} 0.7 \mathrm{Cu}$ paste, containing $13 \%$ flux by weight. Fig. $1 \mathrm{~b}$ presents the pre-designed temperature profiles for the tests. The maximum deviation from these curves in the tests is within $\pm 5 \mathrm{~K}$.

\section{Results}

The first temperature regime studied in reflow experiments is present by Curve 1 in Fig. 1b. It reflects three typical thermal conditions during reflow: temperature increase, dwelling, and cooling. A series of spinning tests are conducted to study the formation of $\mathrm{Ag}_{3} \mathrm{Sn}$ plates starting from the melting point $\left(\mathrm{T}_{\mathrm{m}}\right), 490 \mathrm{~K}$, of the solder material to its final solidification following this temperature profile. Increments between two consecutive tests are controlled with precision of $5 \mathrm{~K}$ and 30 seconds. No trace of $\mathrm{Ag}_{3} \mathrm{Sn}$ plates is observed during entire stages of temperature increase and dwelling. The first time that $\mathrm{Ag}_{3} \mathrm{Sn}$ plates are found is at point $\mathrm{A}(501 \mathrm{~K})$ in the final cooling stage of Curve 1 . Several spinning tests are conducted at this point. $\mathrm{Ag}_{3} \mathrm{Sn}$ IMCs are found in some of these specimens, but not in all, indicating that this point is close to the nucleation point for $\mathrm{Ag}_{3} \mathrm{Sn}$ plates in Curve 1. Figure 2a presents the obtained morphology on the pad at this point. It can be seen that a micro$\mathrm{Ag}_{3} \mathrm{Sn}$ plate is formed in Zone $\mathrm{M}$ on the pad. Focusing on the bottom part of the plate - the 
interface between $\mathrm{Cu}_{6} \mathrm{Sn}_{5}$ IMCs and the plate (Fig. 2b) - it seems that the plate grows from the IMC layer.

The second investigated moment is Point B (493 K) in Fig. 1b, which experiences a further cooling from Point A to a temperature just above the melting point of the eutectic $\mathrm{SnAgCu}$ solder. It presents a transition growth stage of $\mathrm{Ag}_{3} \mathrm{Sn}$ plates. An image of the pad at this point is given in Fig. 2c; it shows that large amounts of small $\mathrm{Ag}_{3} \mathrm{Sn}$ plates are formed. To illustrate the morphology of these plates in detail, a local area of Fig. $2 \mathrm{c}$ is given in Fig. 2d. It can be seen that the plate grows from the IMC interface to the location of the molten solder. In most cases, a plate can have several sub-plates, forming a leaf-like shape at this stage. A characteristic feature of this process is that the angle between these sub-plates is close to $90^{\circ}$, indicating that there are two preferable growth directions in plane. To illustrate the growth behaviour, a plate in Fig. $2 d$ is used for further analysis. It can be seen that there are three sub-plates, which follow this $90^{\circ}$ pattern. The top tip of each subplate is the major growth direction (MGD) of a sub-plate. Along the sub-plate's sides, the front edges have a saw-tooth like profile. The MGD of a saw tooth is parallel to that of an adjacent sub-plate. For instance, the MGD of saw teeth at the edge of sub-plate 1 is parallel to the MGD of sub-plates 2 and 3. The saw tooth profile at the edge is not stable, and can further evolve into a sub-plate (this is discussed below). Thus, a saw tooth presents the initial state of a sub-plate.

In the thickness direction, the $\mathrm{Ag}_{3} \mathrm{Sn}$ plate can be divided into two regions: (i) a transition zone that includes the active faces at the plate's edges; and (ii) the main body with quasi-uniform thickness. In the transition zone, there are generally four (sometimes two) active faces near the tip of a saw tooth or sub-plate. The active face has a flat and 
smooth surface at the micro scale as shown in Fig. 2f. During the growth, $\mathrm{Ag}_{3} \mathrm{Sn}$ can form on this existing surface in some order, maintaining the flat surface and resulting in a sharp blade at the edge. The transition zone is more active in growth. Its evolution controls the growth of the entire plate in the plane direction. In the quasi-uniform thickness zone, the growth in the direction perpendicular to the plate is completed layer by layer. This is demonstrated by several layers, with steps at their edge, formed on the plate as shown in Fig. 2f. Such growth maybe considerably slow, which results in the plate-like morphology of $\mathrm{Ag}_{3} \mathrm{Sn}$ IMCs. To find out the internal lattice orientation of the plate, a transmission electron microscopy (TEM) sample is prepared on the tip of one plate in Fig. 2f. The TEM image and the corresponding diffraction pattern are given in Figs. 3a and b, respectively. $\mathrm{Ag}_{3} \mathrm{Sn}$ IMCs have the orthorhombic crystal structure. The diffraction pattern and energydispersive X-ray (EDX) on TEM confirms that the thinning area is a single crystal of $\mathrm{Ag}_{3} \mathrm{Sn}$. The diffraction pattern also shows that the normals to the (110) and (001) planes are close to the two preferable growth directions (in plane) of $\mathrm{Ag}_{3} \mathrm{Sn}$ plates, respectively.

Figure 2e presents the morphology obtained on the pad at Point C on Curve 1 (485 K), which is between the theoretical melting point and the actual solidification temperature of $\mathrm{Sn} 3.8 \mathrm{Ag} 0.7 \mathrm{Cu}$ solder, and therefore presents the final morphology of $\mathrm{Ag}_{3} \mathrm{Sn}$ plates in the solder bump. As can be seen, $\mathrm{Ag}_{3} \mathrm{Sn}$ plates have grown to a considerably large size at this moment. Some plates reach several hundreds micrometers, which is comparable to the scale of the solder bump. One large plate in Fig. 2e shows that besides a significant growth of the $\mathrm{Ag}_{3} \mathrm{Sn}$ plate along its MGD, a small saw-tooth structure at the external edge has grown into large ones. Some of them become individual sub-plates. This phenomenon is more 
pronounced in Figs. 4e and 4f, which are also obtained at a temperature (485 K) below $\mathrm{T}_{\mathrm{m}}$ (Point $\mathrm{J}$ on Curve 2). The long needle-like reactants in Fig. 2e is $\mathrm{Cu}_{6} \mathrm{Sn}_{5} \mathrm{IMCs}$.

\section{Discussions}

To find the formation scenario for $\mathrm{Ag}_{3} \mathrm{Sn}$ plates, several more thermal conditions during reflow are investigated: (i) a continuous temperature increasing from $\mathrm{T}_{\mathrm{m}}$ to Point $\mathrm{F}$ (538 K) following Curve 3 in Fig. 1b; (ii) dwelling at $518 \mathrm{~K}$ for about 25 mins from Point D to E in Fig. 1b; and (iii) secondary reflow of a solidified specimen (without spinning) to the maximum temperature (Point G, $527 \mathrm{~K}$ ) of Curve 1 in Fig. 1b. No $\mathrm{Ag}_{3} \mathrm{Sn}$ plates are observed in these tests. In the first two cases, $\mathrm{Ag}_{3} \mathrm{Sn}$ plates are not generated. In the last one, $\mathrm{Ag}_{3} \mathrm{Sn}$ that is generated during the first reflow is dissolved. Under conditions of the increasing temperature and dwelling, the substrate is consumed, which increases the $\mathrm{Cu}$ content in the liquid solder. According to the concept of local nominal composition (LNC) [13], the ratio of Sn to Ag remains the same in the "filler" material. Following this evolution, $\mathrm{Ag}_{3} \mathrm{Sn}$ cannot be generated according to the $\mathrm{SnAgCu}$ equilibrium phase diagram. When the temperature decreases, $\mathrm{Cu}_{6} \mathrm{Sn}_{5}$ IMCs precipitate from the liquid solder at the interface [14], which consumes both $\mathrm{Cu}$ and $\mathrm{Sn}$, and, correspondingly, increases the $\mathrm{Ag}$ content at the local area near the solder/substrate interface. When the composition reaches a certain value, $\mathrm{Ag}$ begins to precipitate in the form of $\mathrm{Ag}_{3} \mathrm{Sn}$ IMCs. Therefore:

(i) $\mathrm{Ag}_{3} \mathrm{Sn}$ IMC plates are only formed under a decreasing temperature, and in the middle of the cooling stage rather than at the beginning;

(ii) $\mathrm{Ag}_{3} \mathrm{Sn}$ IMCs nucleate predominantly at the solder/substrate interface; 
(iii) Under a condition of temperature increasing in the secondary reflow, interfacial CuSn IMCs are dissolved [14]; Solubility of $\mathrm{Ag}$ in the molten solder increases. Therefore, $\mathrm{Ag}_{3} \mathrm{Sn}$ IMCs are also dissolved in the secondary reflow.

To verify this analysis, a different temperature profile, Curve 2 in Fig. 1b, is used for the tests to investigate the formation behaviour of $\mathrm{Ag}_{3} \mathrm{Sn}$ IMCs. Again, $\mathrm{Ag}_{3} \mathrm{Sn}$ IMCs is first found in the middle of the cooling stage (Point H, $501 \mathrm{~K}$ ). Similar growth behaviour is achieved in the subsequent cooling stage as shown in Fig. 4. The temperature of Point I is $493 \mathrm{~K}$. Figure $4 \mathrm{c}$ shows that $\mathrm{Ag}_{3} \mathrm{Sn}$ plates are formed in all types of orientation with two or three sub-plates. The specific number of sub-plates is influenced by the orientation of the plate. As analyzed, there are two preferable growth directions for a plate. If one of these directions is parallel or nearly parallel to the $\mathrm{Cu}$ substrate, three sub-plates can be formed on one plate, two of them being directly connected to the $\mathrm{Cu}$ pad. In other orientations, two sub-plates are formed. Some of these features are consumed by a further growth as shown in Fig. 4e.

It should be noted that the experimental approach can only capture reactants that are still connected to the $\mathrm{Cu}$ substrate. There is possibility that $\mathrm{Ag}_{3} \mathrm{Sn}$ IMCs are formed in the body of the liquid solder bump, but are removed during spinning.

\section{Conclusions}

This paper presents the formation behaviour of $\mathrm{Ag}_{3} \mathrm{Sn}$ plates in the eutectic $\mathrm{SnAgCu}$ $\mathrm{Pb}$-free solder bump during the entire process of reflow. The results show that under all investigated temperature conditions, including the increasing temperature, dwelling and secondary reflow, $\mathrm{Ag}_{3} \mathrm{Sn}$ plates are only formed starting at the middle of the cooling stage 
of the reflow. This explains why the high cooling rate can suppress their formation: it limits their growth time. The results also show that these plates nucleate preferably at areas near the solder/substrate interface. However, there is possibility that plates are formed away from the interface, and are not present due to the nature of the applied technique; In the plane, $\mathrm{a} \mathrm{Ag}_{3} \mathrm{Sn}$ plate has two preferable growth directions, which are close to the normals to the (110) and (001) planes, respectively.

\section{Acknowledgments}

The financial support from the Engineering and Physical Sciences Research Council's Innovative Manufacturing and Construction Research Centre at Loughborough University, UK under GR/R64483/01P is gratefully acknowledged.

\section{References}

[1] J. Lee, D. Park, J. Heo, Y. Lee, D. Shin, Y. Kim, Scr. Mater. 42 (2000) 827.

[2] M. Kerr, N. Chawla, Acta Mater. 52 (2004) 4527.

[3] A.R. Fix, G.A. López, I. Brauer, W. Nüchter, E.J. Mittemeijer, J. Electron. Mater. 34 (2005) 137.

[4] K. Zeng, K.N. Tu, Mat. Sci. Eng. R 38 (2002) 55.

[5] L.P. Lehman, S.N. Athavale, T.Z. Fullem, A.C. Giamis, R.K. Kinyanjui, M. Lowenstein, K. Mather, R. Patel, D. Rae, J. Wang, Y. Xing, L. Zavalij, P. Borgesen, E.J. Cotts, J. Electron. Mater. 33 (2004) 1429.

[6] K.N. Tu, A.M. Gusak, M. Li, J. Appl. Phy. 93 (2003)1335. 
[7] D.W. Henderson, T. Gosselin, A. Sarkhel, S.K. Kang, W. Choi, D. Shih, C. Golsmith, K.J. Puttlitz, J. Mat. Res. 17 (2002) 2775.

[8] K.S. Kim, S.H. Huh, K. Suganuma, J. Alloy. Compd. 352 (2003) 226.

[9] K.S. Kim, S.H. Huh, K. Suganuma, Mater. Sci. Eng. A 333 (2002) 106.

[10] H.Y. Lu, H. Balkan, K.Y.S. Ng, Microelectron. Reliab. 46 (2006) 1058.

[11] S. Kang, A.K. Sarkhel, J. Electron. Mater, 23 (1994) 701.

[12] K.S. Kim, S.H. Huh, K. Suganuma, Microelectron. Reliab, 43 (2003) 259.

[13] K. Rönkä, F.J.J. van Loo, J.K. Kivilahti, Scr. Mater. 37 (1997) 1575.

[14] J. Gong, C. Liu, P.P. Conway, V.V. Silberschmidt, Acta Mater. 56 (2008) 4291.

\section{Figure Captions}

Fig. 1 (a) Sketch of the experimental set-up; (b) Temperature profiles during reflow. Cooling rate is $30 \mathrm{~K} / \mathrm{min}$ for Curves 1 and 2. Points A, B, C, D, E, F, G, H, I and J are at $501 \mathrm{~K}, 493 \mathrm{~K}, 485 \mathrm{~K}, 518 \mathrm{~K}, 518 \mathrm{~K}, 538 \mathrm{~K}, 527 \mathrm{k}, 501 \mathrm{~K}, 493 \mathrm{~K}$ and $485 \mathrm{~K}$, respectively.

Fig. 2 Formation of $\mathrm{Ag}_{3} \mathrm{Sn}$ plates for different points of Curve 1 in Fig. 1b. (a), (c), (e) and (f) are obtained at Points A, B, C and B respectively; (b) and (d) are local areas of (a) and (c), respectively. (f) is not a local area of (c).

Fig. 3 (a) TEM image of the tip of the $\mathrm{Ag}_{3} \mathrm{Sn}$ plate in Fig. $2 \mathrm{f}$, and (b) diffraction pattern at the thinned area. Points $\mathrm{N}, \mathrm{O}$ and $\mathrm{P}$ in (a) and Fig. $2 \mathrm{f}$ show the relative position of the tip. Fig. 4 Formation of $\mathrm{Ag}_{3} \mathrm{Sn}$ plates along Curve 2 in Fig. 1b. (a), (c) and (e) are obtained at Points H, I and J, respectively; (b), (d) and (f) are local areas of (a), (c) and (e), respectively. 


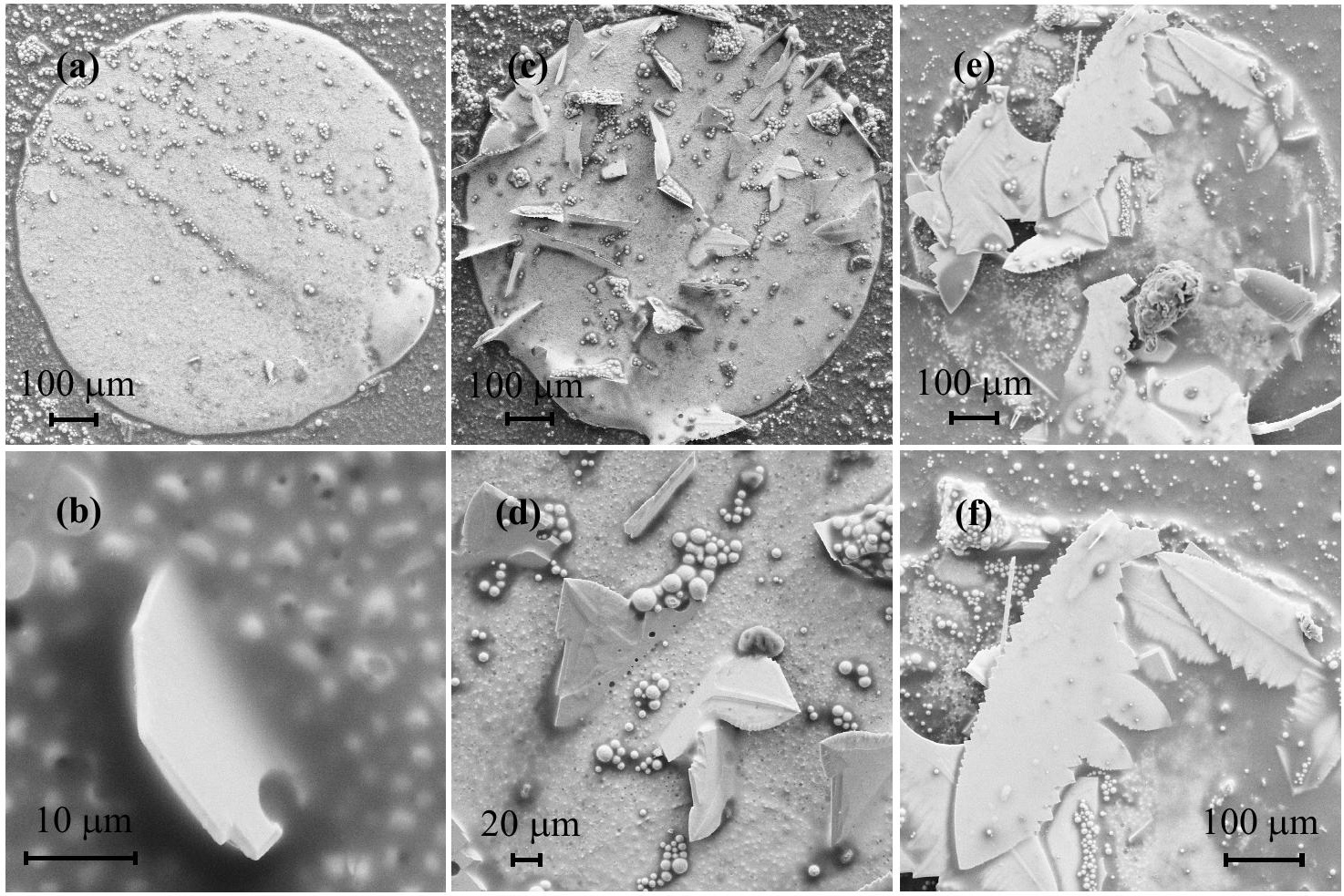




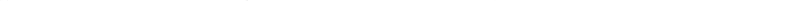




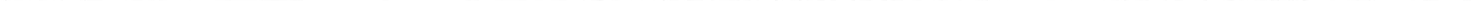


(a)

Oven

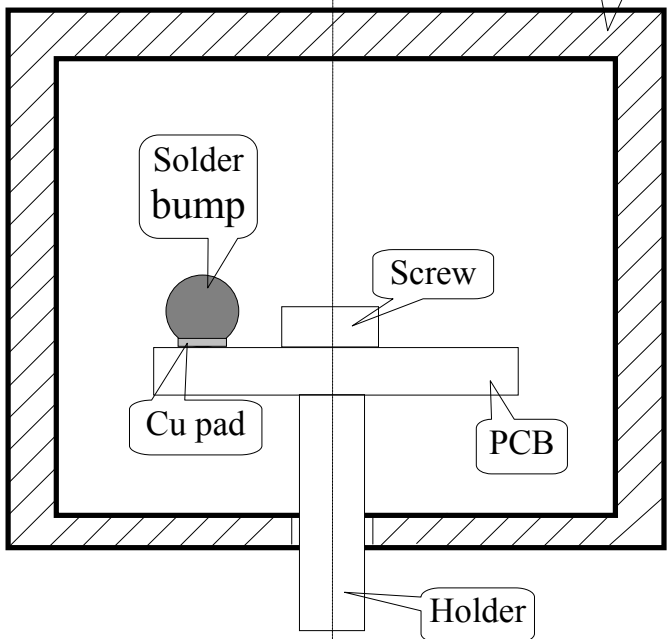

(b)

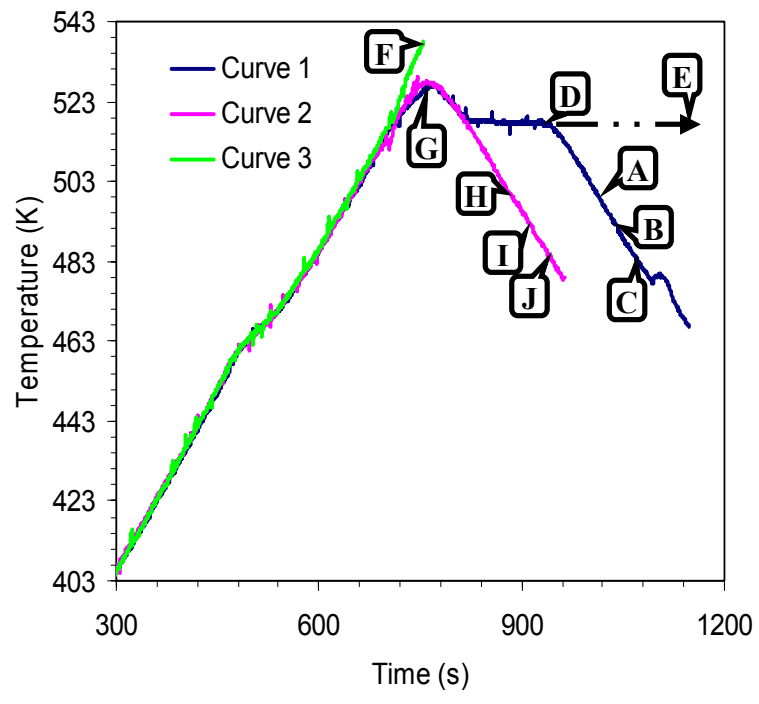

